\title{
AVALIAÇÃO DA ATIVIDADE ANTIOXIDANTE DE Pfaffia glabrata
}

\section{Tamiris Rocha Fanti Raimundo' \\ Marcos J. Salvador ${ }^{2}$ \\ Wallace Ribeiro Corrêa ${ }^{3}$}

Resumo: Plantas do gênero Pfaffia pertencente à família Amaranthaceae, são conhecidas popularmente como "Ginseng brasileiro" ou "para tudo", devido a sua alta eficiência em diversos tratamentos. Desta forma, o presente trabalho teve por objetivo avaliar a atividade antioxidante de extratos da espécie Pfaffia glabrata utilizando os métodos DPPH e FOLIN. Em uma avaliação inicial, o extrato etanólico de P. glabrata apresentou um melhor nível de compostos fenólicos (2.20 mg GAE/g) e atividade antioxidante (IC50 = $169,39 \mu \mathrm{g} / \mathrm{mL}$ no DPPH). Mediante aos resultados apresentados pelos extratos da planta, concluiu-se que a espécie apresenta uma atividade antioxiodante significativa, na qual, está correlacionada ao nível de compostos fenólicos encontrados.

Palavras-chave: Pfaffia glabrata; Amaranthaceae; atividade antioxidante.

\footnotetext{
1 Curso de Licenciatura em Ciências Biológicas/ IFSULDEMINAS Campus Inconfidentes, Brasil. E-mail: tamirisrfanti@hotmail.com.

2 Curso de Farmácia, Departamento de Biologia Vegetal, Instituto de Biologia/ UNICAMP, Brasil. E-mail: marcosjs@unicamp.br.

3 Departamento de Desenvolvimento Educacional/ IFSULDEMINAS Campus Inconfidentes, Brasil. E-mail: crwallace@bol.com.br.
} 